\title{
A enunciação na encenação teatral
}

\author{
Janaína de Mello FERNANDES (USP)
}

RESUMO: Pesquisar a enunciação na encenação teatral implica investigar como se dá o diálogo entre o conjunto de elementos formadores da encenação e a platéia. Focada no nível discursivo do percurso gerativo do sentido, esta pesquisa analisa os efeitos de distanciamento e aproximação causados nessa relação, baseada em gêneros teatrais diversos.

PALAVRAS-CHAVE: semiótica; teatro; enunciação; encenação; discurso.

ABSTRACT: Researching the enunciation in theater staging meets the investigation on how the elements in scene and the audience combine on stage. This research focus the speech level which generates a sense to the scene itself and analyzes the distance and approaches into that relation based on various theater genres.

KEYWORDS: semiotics; theater; enunciation; staging; speech. 


\section{A encenação teatral}

Formada do prefixo en (movimento para dentro, colocação em) somado ao elemento scena (pátio, episódio, espetáculo) e ao sufixo -ção (ação, resultado de ação), a palavra encenação diz respeito ao ato de pôr em cena (espetáculo). Já o termo teatro carrega dois sentidos fundamentais: o imóvel, edifício onde acontecem os espetáculos, dotado principalmente de um espaço para a platéia e do palco, e a manifestação artística, transmitida ao público por meio da encenação. A etimologia grega da palavra teatro dá ao termo o sentido de miradouro, lugar de onde se pode ser visto. Um espetáculo teatral existe quando um público ouve e vê uma representação, sendo essas bases essenciais para a existência dessa manifestação artística. Assim, a encenação teatral une diversas formas de arte - como literatura, artes plásticas, expressão corporal - e as tira de sua instância usual para que juntas formem um espetáculo teatral.

A encenação teatral pode ser então entendida como a manifestação cênica de um discurso, utilizando elementos visuais e sonoros, a partir de uma idéia principal. Para sustentar esse discurso, há na encenação um conjunto de componentes com diferentes linguagens que carregam, à sua forma, imagens capazes de remeter àquela idéia. São eles: a arquitetura teatral - organização do espaço cênico (teatro de rua, teatro de arena, palco italiano, construções inovadoras da sala de teatro) -; a ambientação visual e sonora - cenografia, iluminação, figurinos, acessórios, sonoplastia e música -; o texto verbal - que pode estar mais ou menos presente de acordo com a estética teatral em questão, embora sua própria ausência constitua forma de expressão teatral -; o trabalho do ator - aquele que vivencia a encenação -; o trabalho do diretor - que organiza todos esses elementos a fim de sintetizar as imagens sincréticas para uma significação una e coesa.

Dessa forma, para se analisar a encenação teatral, é preciso considerar todos os seus elementos e a forma como eles se organizam na realização do espetáculo. A partir dessa análise, será possível estabelecer como se dá a relação entre a encenação e a platéia, de acordo com as escolhas tomadas ao se conceber uma peça, geralmente vinculadas a determinado gênero teatral.

\section{A abordagem semiótica}

A semiótica discursiva pode ser entendida como a teoria capaz de analisar qual(is) o(s) efeito(s) de sentido produzido(s) por um texto e de que forma este o(s) produz. Para estabelecer os mecanismos pelos quais ocorre a construção do sentido em um texto, condiciona seu plano de conteúdo ao percurso gerativo do sentido, dividido em três níveis que vão do mais simples e abstrato ao mais complexo e concreto. São eles: nível fundamental, simples e abstrato, no qual se estabelece uma oposição semântica mínima; nível narrativo, preocupado com o sujeito e suas relações juntivas com o objeto; e nível discursivo, em que se concretizam os dois níveis anteriores, imbuídos de pessoa, tempo e espaço. É neste último que se concentra grande parte desta pesquisa, preocupada em analisar a enunciação de uma encenação teatral.

O nível discursivo é, portanto, o mais externo dos níveis, em que as categorias apresentadas no nível semio-narrativo (constituído dos níveis fundamental e narrativo) são tematizadas e figurativizadas e ganham as dimensões de pessoa, tempo e espaço. É o nível mais aparente quando se lê um livro, vê um quadro ou assiste a uma peça de 
teatro, pois é nele que as relações dos níveis anteriores são colocadas em discurso, por meio da enunciação. Nessa enunciação, definem-se o enunciador e o enunciatário e a relação entre estes produz o enunciado.

Há, então, a sintaxe do nível discursivo, formada pela colocação das categorias de pessoa, tempo e espaço. Essa sintaxe é revestida de uma semântica ao ser discursivisado um ou mais temas, que podem ou não estar recobertos de figuras. Assim, as figuras constituem o que se pode chamar de o degrau mais alto do plano do conteúdo.

Em $O$ círculo de giz caucasiano, de Bertolt Brecht, o tema da posse de terras é revestido pelo percurso figurativo da disputa entre as "duas mães" pela criança herdeira. A camponesa sempre cuidou da criança que fora abandonada, e a mãe biológica volta para buscá-la ao descobrir sua herança. O que Brecht quer mostrar é que a terra deve ser de quem a cultiva, não de quem a possui. Revestindo seu percurso temático por essas figuras, o autor acrescenta a seu texto elementos mais sensíveis ao seu interlocutor. Mas esse texto não é apenas um texto literário, é uma peça teatral, e para ser montada exigirá que um percurso figurativo revista todos os seus elementos.

Um texto verbal figurativiza seu percurso temático incidindo sobre as categorias sintáticas de pessoa, tempo e espaço do discurso (no caso das pessoas na obra citada, por exemplo, o proprietário de terras e o camponês são figurativizados respectivamente pela mãe biológica e pela mãe de criação). Na encenação teatral, esse processo deve expandir o nível textual e atingir todos os outros componentes. Ou seja, além de estarem presentes no texto escrito, essas figuras devem aparecer no cenário, na iluminação, no figurino, nos acessórios, na interpretação dos atores, na sonoplastia. A encenação teatral, então, manifesta as figuras realizadas no discurso. É essa manifestação, que une todos os elementos em torno de um mesmo percurso figurativo, a responsável pela coesão em um espetáculo teatral (mesmo que esta coesão implique um não-entendimento).

\section{O verbal e o não-verbal na encenação teatral}

A encenação teatral apresenta-se, então, como uma manifestação artística complexa, em que elementos verbais e não-verbais coexistem em uma espécie de interdependência, pois não deve ser possível dissociá-los durante uma representação.

$\mathrm{O}$ elemento verbal principal é o texto escrito, que na encenação passa à instância de fala. Assim, ganha forma na entonação empregada pelos atores e começa a exigir da platéia um reconhecimento auditivo, referente à simples elocução da fala, e visual, no que diz respeito aos gestos e à expressão corporal dos atores, os quais muitas vezes servem de grifo ao texto. Além disso, algumas estéticas teatrais podem fazer uso do texto escrito propriamente dito, aplicando-o em placas expostas à platéia, geralmente para algo que deve ser assimilado pelo público sem a interferência das personagens. $\mathrm{O}$ não-verbal pode ser percebido no cenário, no figurino, na sonoplastia, na iluminação, nos acessórios e mesmo na expressão corporal dos atores.

Em um texto escrito, componente verbal da encenação, as escolhas de pessoa, tempo e espaço realizadas no nível discursivo provocam os efeitos de distanciamento ou de aproximação. Assim, os enunciados construídos em primeira pessoa, no tempo presente e no lugar do aqui são tidos como subjetivos, produzindo efeito de aproximação, e advêm de uma enunciação de debreagem enunciativa; já aqueles 
construídos na terceira pessoa, no tempo do então e no espaço do lá são chamados objetivos, responsáveis pelo efeito de distanciamento, e são oriundos de uma enunciação de debreagem enunciva.

A encenação teatral, no entanto, não é composta apenas de elementos verbais. Por ser constituída de uma série de fatores, misturando verbais e não-verbais em uma só representação, apresenta-se como uma manifestação artística sincrética. Assim, fica mais difícil delimitar qual o signo de uma encenação teatral. Qual sua unidade significante? Quais os limites entre plano da expressão e plano de conteúdo? Entre figurino e cenário? Gesto e maquiagem? Há aí um problema com um conceito que vem da lingüística e precisa ser ajustado a uma representação tão complexa. Percebe-se que a relação enunciador-enunciatário em uma encenação teatral não pode ser analisada nos mesmos termos de um texto verbal, posto que um conjunto de elementos diverso forma o enunciador que é a encenação teatral. Ou seja, não devem ser levados em conta apenas os pronomes utilizados no discurso do texto escrito, mas qual o efeito que esses pronomes em harmonia (ou desarmonia) com os outros elementos da encenação - como o cenário, o figurino e o trabalho dos atores - são capazes de produzir. O que se investiga é o efeito de aproximação e distanciamento existente entre peça teatral e platéia. Assim, na enunciação da encenação teatral, a peça em seu todo assume o papel de enunciador, e a platéia, de enunciatário.

\section{O estatuto semiótico da encenação teatral}

Alicerçado em termos dos efeitos de aproximação e distanciamento, este estatuto utiliza quatro teatrólogos e suas estéticas teatrais como exemplo do que poderia ser chamado de Teatro da Aproximação, Teatro da Não-aproximação, Teatro do Distanciamento e Teatro do Não-distanciamento. São eles, respectivamente: Antonin Artaud e o Teatro da Crueldade; Constantin Stanislavski e o Teatro Psicológico; Bertolt Brecht e o Teatro Épico e; Vsiévolod Meyerhold e seu teatro construtivista.

Todos têm muita coisa em comum, apesar das diferenças, mas a semelhança mais importante para essa análise consiste em sua relação com o Teatro Psicológico. Stanislavski é o criador dessa estética, e, portanto, seu defensor. Os outros três estudados, porém, partem do princípio de que esse gênero é ineficiente, ou pelo menos insuficiente, para seus objetivos. Então, cada teatrólogo empenhará sua criação nos pontos respectivos de discordância com o teatro psicológico, o que produzirá três gêneros distintos.

Partiremos, então, para uma análise desses quatro gêneros, a partir dos elementos que os compõem.

\section{1. O Teatro da Aproximação}

A estética teatral escolhida para exemplificar o efeito de aproximação causado por uma encenação teatral, enquanto enunciador, ao seu enunciatário (a platéia) foi o Teatro da Crueldade, de Antonin Artaud.

Artaud abole definitivamente a sala italiana. Para realizar a aproximação, propõe que o espectador sente-se no centro do espaço, em cadeiras giratórias, enquanto a ação realiza-se em diferentes níveis e direções, permitindo a simultaneidade das ações e o envolvimento físico do público com o espetáculo. Além disso, dá grande 
importância aos objetos, dando a eles o poder de causar sensações e trazer lembranças ao espectador, as quais ele nem lembrava que possuía. Para tanto, utiliza-se de manequins, máscaras, bonecos imensos, etc...

Artaud também vai mudar a concepção de iluminação. Contra uma luz atmosférica, propõe outra capaz de provocar sensações. Para ele, devem ser procurados efeitos de vibrações luminosas, produzindo novas ondas, criando novas cores, com o objetivo de produzir calor, frio, raiva, medo, etc.

No Teatro da Crueldade, o figurino torna-se objeto e assemelha-se aos bonecos enormes por constituir-se de vestimenta ritualística. Ambos estão em cena com a mesma importância das imagens verbais. O caráter ritualístico do teatro artaudiano é mais um fator que corrobora a aproximação, já que tem a intenção de trazer consigo signos esquecidos, que provocam sensações por fazerem parte de antigas tradições e resgatam o sentido verdadeiro da encenação.

O teatro artaudiano é também um espetáculo musical. Deve estar repleto de sons desconhecidos ou esquecidos, além dos sons vocais, que se assemelham aos instrumentais, produzindo ruídos quase não-humanos. Em Artaud, a voz é uma fonte de energia sonora, capaz de atingir os nervos e os sentidos do espectador. O som é amplificado, abrangente, para alcançar as dimensões extraordinárias dos bonecos e objetos.

Artaud rompe definitivamente com o texto escrito no Teatro da Crueldade. Aqui, as palavras conservam seu efeito sonoro e encantatório, deixando de lado, na maioria das vezes, seu valor cognitivo. Quando há a cognição, esta não é de maior importância frente aos outros elementos da encenação, nem conta histórias ou qualquer coisa que mantenha seu sentido em forma escrita.

O ator do Teatro da Crueldade é apenas mais um instrumento do espetáculo. É um veículo de sensações e deve transportar impulsos sensitivos ao espectador até que este atinja o transe. É ele que deve fazer o espectador gritar. Mas para obter sucesso em sua performance o ator deve saber em que músculo reflete-se cada sentimento, de que forma respira cada sensação. Por isso não deve entrar em transe. Deve, sim, dispor do que Artaud chama de "atletismo afetivo", considerando o ator um "atleta do coração".

Uma tendência marcante do teatro moderno foi o gradativo enfraquecimento da imagem do diretor na encenação teatral. A concepção dos elementos cênicos continua vinculada à imagem do diretor, mas a interpretação do ator já está desvinculada. No Teatro da Crueldade, a improvisação do ator com os elementos cênicos é bastante intensa, o que faz do diretor um personagem atido especialmente à organização dos constituintes da encenação.

Assim, todo o Teatro da Crueldade volta-se para a aproximação, com o intuito de fazer o espectador acordar da inércia provocada pelo Teatro Naturalista e interagir com o espetáculo, provocando-lhe sensações. Imaginemos um teatro que não seja uma sala, mas um balcão. Nele, o espectador é envolvido por jogos de luzes, ruídos inauditos, bonecos gigantes, palavras inéditas, atores-marionetes... Tudo trazendo um clima dos antigos rituais. Aqui há a quebra, não para provocar entendimento, mas uma confusão de sensações. $O$ espectador deve sentir até não agüentar mais e gritar e expurgar as emoções que vem interiorizando há anos. Será sempre surpreendido com novas emoções até entrar em transe. Essa é a enunciação do teatro de Artaud, um teatro 
do plano da expressão, todo paixões e tudo ao mesmo tempo, para que o enunciatário desperte no susto e, quando for embora, reaprenda a pensar e tome consciência do mundo.

\section{2. O Teatro da Não-aproximação}

Para servir de exemplo a uma estética teatral cuja relação entre encenação e platéia seja a da não-aproximação, foi escolhido o Teatro Realista/Naturalista, também chamado Teatro Psicológico, de Stanislavski. Esse gênero teatral domina as escolas de teatro até os dias de hoje, por mais que outros pensadores e outras estéticas tenham surgido com o passar dos anos. De qualquer forma, contra ou a favor do teatro psicológico, este se constitui como um marco e qualquer nova teoria teatral parte de sua negação ou afirmação.

A encenação no Teatro Realista/Naturalista deve servir como um espelho da realidade, processo semelhante ao que ocorre com as outras manifestações artísticas e literárias do naturalismo. Assim, o que é excessivamente descritivo em um romance também o é na encenação teatral. Nada escapa aos detalhes de um encenador do teatro psicológico. Desde a renda de uma cortina ao drama vivenciado pela personagem (por isso a denominação "psicológico"), tudo deve estar muito evidente para a platéia.

Neste tipo de encenação, a platéia deve identificar-se com a peça, mas jamais deverá tomar parte dela. Para não correr esse risco, Stanislavski estabelece o que chama de "quarta parede". Uma parede imaginária entre o palco e a platéia, para mantê-los a uma distância segura.

O palco utilizado é o italiano, composto de um tablado graças ao qual a encenação acontece em um nível superior ao da platéia. Em relação frontal, o público acomoda-se e assiste à peça. Por toda a volta do palco coxias separam os bastidores da encenação, pois tudo deve parecer real. O cenário deve ser composto de elementos que remetam fielmente aos objetos mencionados no texto. Uma sala, por exemplo, deve conter sofás, tapetes, janelas, tudo o que for necessário para que o espectador possa acreditar que se trata realmente de uma sala, com todos os seus detalhes.

A iluminação também deve ser fiel à realidade. Se é noite, escura; se é dia, clara. Se há um abajur, foco sobre ele quando estiver aceso. A luz do sol deve entrar pela janela descortinada. Além disso, a iluminação serve também para dar o clima ao Teatro Psicológico, fazendo com que os sentimentos das personagens possam ser perfeitamente compreendidos pela platéia. A sonoplastia auxilia esse efeito, transmitindo os dramas psicológicos das personagens.

As vestimentas no teatro psicológico devem parecer roupas de verdade, sem o menor caráter de figurino, para não interromper a identificação do público.

O texto verbal é importantíssimo no Teatro Psicológico. Uma peça representada nesses moldes pode ser apenas lida que será perfeitamente compreendida. Nessa estética, o texto escrito tem certa autonomia sobre os outros elementos da encenação.

Os atores do Teatro Realista devem esquecer completamente seus conceitos e assumir os das personagens. Devem representar de forma que o espectador acredite tratar-se de realidade. Mas o ator não pode se esquecer da quarta parede, pois é ela que permite a identificação do público sem que este faça parte da encenação. Ao contrário, a 
platéia deve permanecer estática, como quem observa a realidade sem tomar partido, como quem olha pelo buraco da fechadura.

É o diretor que coordena a montagem da encenação naturalista. Toda a elaboração dos elementos cênicos e a interpretação dos atores submetem-se ao texto escrito e à concepção do diretor.

Assim, no Teatro Realista/Naturalista, o que se pretende é a identificação do público, para que este perceba o drama psicológico das personagens, por isso é também chamado de Teatro Psicológico. Não há quebras no decorrer da apresentação, a não ser aquelas previstas pela sinopse do texto escrito, ao qual esta estética mostra-se extremamente presa. O teatro naturalista também quer despertar a consciência do espectador. Para os teatrólogos e diretores que optam por essa estética, a identificação é a melhor forma de conscientização, pois, observando a representação fiel dos fatos, a platéia toma conhecimento da realidade em que se encontram todas as esferas da sociedade.

Dessa forma, o Teatro Realista/Naturalista mostra-se como uma estética da não-aproximação ao inserir a quarta parede que afasta a platéia. Ainda assim, a relação estabelecida entre enunciador e enunciatário não chega a ser a de distanciamento, pois a identificação provocada na platéia confere uma certa proximidade, bloqueada apenas no limite da quarta parede.

\section{3. O Teatro do Distanciamento}

O teatro brechtiniano foi o escolhido para elucidar o que seria um efeito de distanciamento produzido entre a encenação e a platéia. No teatro de Brecht, Teatro Épico, ainda há a importância do texto (uma peça brechtiniana pode ser apenas lida silenciosamente que seu sentido não será perdido). A inovação aqui se dá com maior ênfase na encenação. Já que o público não pode se identificar com as personagens, deve ficar bem claro que se trata de uma peça teatral, uma representação. É o chamado distanciamento.

O teatro brechtiniano conserva a "estrutura italiana" do Teatro Naturalista, mas distorce-a. Criando uma nova concepção do espaço, despe essa estrutura de tudo o que considera inútil, para depois vesti-la com o que lhe é necessário. $\mathrm{O}$ palco agora não apresenta mais um cenário que corrobore o ilusionismo do espectador, muito pelo contrário, fazem parte dele os andaimes, equipamentos técnicos, escadas, cortinas, enfim, toda a estrutura do palco está à mostra. Há ainda a presença de um telão e de placas que entrecortam a ação, levando mensagens para lembrar o espectador de que o que se passa é apenas uma representação. Todos esses elementos convergem para um ponto em comum: o distanciamento, por meio do qual Brecht procura provocar a conscientização do espectador.

Em Brecht, a iluminação é utilizada apenas para tornar o espetáculo visível, sem criar atmosferas ou a lembrança de algum ambiente do cotidiano. Este tipo de encenação utiliza uma luz branca, forte e chapada, que ilumina por inteiro; ou mesmo a ribalta, que ilumina de baixo para cima, ambas provocando o afastamento total do realismo cênico.

O figurino de Brecht carrega consigo o conteúdo sócio-histórico de suas peças. Em Mãe Coragem, por exemplo, que se passa na década de 1930, durante a guerra, os 
figurinos são cinzentos, lembrando a guerra, a fome... Ao mesmo tempo, deve ter caráter de figurino, um caráter espetacular conseguido com o que Brecht chama de "disfarces particularmente exagerados".

O som também é utilizado para produzir o distanciamento. A música épica é música de teatro. Em vez de dar ênfase a uma atmosfera, ela marca as quebras, novamente para que fique claro tratar-se de um espetáculo teatral. A orquestra encontrase no palco e a música acontece em números isolados. São os songs, em que os atores distanciam-se de seus personagens e dirigem-se frontalmente ao público.

Apesar de criticar a hegemonia do texto no Teatro Naturalista, Brecht não o elimina do Teatro Épico, apenas modifica a maneira de utilizar-se dele. Há diversas intervenções no texto, como os songs e as placas, já mencionados. Quando o ator canta o song, sua personagem é momentaneamente deixada de lado para lembrar que ela é apenas uma simulação do real. Freqüentemente, o discurso do song comenta o discurso da personagem. Os cartazes anunciam os quadros e as ações, ou até mesmo introduzem os songs, intitulando a canção.

Para representar o Teatro Épico, é preciso um novo tipo de ator, e, para isso, novas técnicas de representação. $\mathrm{O}$ ator deve fazer com que o espectador questione-se sobre as atitudes das personagens, sobre suas ações, suas relações sociais. Deve livrar o espectador do ilusionismo, sem jamais imitar a realidade, mas mostrar como enxergá-la, por meio das técnicas do distanciamento.

Como o Teatro Épico é bastante específico em suas intenções, se o diretor pretender ser fiel ao efeito de distanciamento e ao sentido que este produz, terá pouca liberdade de criação, já que os parâmetros da encenação brechtiniana estão categoricamente definidos em cada obra.

Assim, talvez esteja nos songs, e na forma como são representados, a maior demonstração de distanciamento. Imaginemos um teatro tradicional com as coxias abertas, por trás vê-se toda a estrutura, no palco uma luz geral e chapada. Além dos atores e de alguns objetos necessários, uma orquestra. Tudo pode parecer muito frio, mas o texto é político e marxista, portanto fala do povo, da miséria, da desigualdade social, e com um toque de comicidade. Quando o espectador já se emocionou e está preste a identificar-se com a personagem (como vinha acostumado a fazer), a luz chapada movimenta-se e ilumina uma placa com um título escrito, a orquestra começa a tocar, o ator muda seu trabalho corporal e, apesar do figurino ainda ser da personagem, vê-se que ela não está mais ali. Então, ele começa a cantar tecendo comentários sobre a peça, e o enunciatário, que já se apaixonou, em vez de simplesmente entregar-se, vai pensar e tomar consciência das informações que lhe estão sendo passadas. Essa é a enunciação no Teatro Épico, em que todos os elementos do enunciado agem em conjunto para persuadir o enunciatário, que deve se apaixonar, sim, mas logo ser surpreendido, para que saia da inércia do sentir e aja.

\section{3. 1. A ironia do teatro brechtiniano}

Há ainda um elemento complexo utilizado por Brecht para produzir o efeito de distanciamento em sua encenação. Parece estranho ao leitor atento o fato de que, para causar o distanciamento, os atores devem dirigir-se à platéia (por meio dos songs). Não 
seria isso uma aproximação? O rompimento da quarta parede do teatro psicológico que tirasse a encenação do estado de não-aproximação para o de aproximação?

$\mathrm{Na}$ verdade, quando os atores dirigem-se à platéia, eles mesmos se distanciaram de suas personagens. Há então uma aproximação ilusória apontando para a encenação que está "lá", mas representa o "aqui". Para o teatro brechtiniano, o naturalismo de Stanislavski impedia a associação da platéia entre a ficção alegórica da peça e a realidade dos acontecimentos sociais. Por isso, faz-se necessário que os atores, livres das personagens, dirijam-se à platéia para mostrar que a encenação é mesmo uma encenação, não sendo possível identificar-se com ela, embora a realidade esteja bem próxima da história que está sendo contada ali. Assim, a encenação subordina o texto escrito ao conjunto de elementos responsáveis pelo distanciamento da cena e afasta a platéia. O que ocorre, então, é um afastamento entre a enunciação e o enunciado.

Dessa forma, em um processo semelhante ao da ironia, o Teatro Didático diz uma coisa querendo dizer o seu contrário. Assim como na língua essa inversão é percebida por um traço pragmático e uma certa mudança na entonação do discurso, na encenação brechtiniana ocorre a quebra e a mudança de foco da cena. Então, no exato momento em que o ator se aproxima, a encenação produz na platéia o efeito de distanciamento. A aproximação, então, torna-se para Brecht um objeto modal para atingir o distanciamento, e como a ironia, nega no enunciado e afirma na enunciação.

\section{4. O Teatro do Não-distanciamento}

O teatrólogo russo Meyerhold foi o escolhido para exemplificar uma estética teatral que mantenha com seu enunciador uma relação de não-distanciamento. Ou seja, que negue o distanciamento entre encenação e platéia, mas não chegue a afirmar a aproximação artaudiana, na qual a platéia faz parte da encenação.

Meyerhold começou sua carreira no Teatro de Arte de Moscou, como aluno de Stanislavski. Farto do naturalismo, vai em busca do futurismo, impressionismo, cubismo e expressionismo alemão. O teatro de Meyerhold tem o objetivo de reestruturar a realidade, e para isso utiliza elementos absurdos e quebras na lógica de seus trabalhos. A partir de pesquisas com a Commedia Dell'arte, as improvisações, o grotesco e a pantomima, desenvolve uma nova estética teatral, na qual ator, autor, diretor e público são os criadores do fenômeno teatral. Mas a participação do público deve ser apenas emocional, nunca física. Usando a imaginação, a platéia deve preencher as lacunas deixadas na encenação, passando da simples contemplação do Teatro Realista/Naturalista ao ato criador.

Assim, a encenação deixa de ser uma cópia do real e se torna uma reflexão sobre a realidade. Elimina-se a quarta parede, possibilitando a relação entre enunciador e enunciatário, forçando o espectador a reestruturar a realidade. Esse novo modelo de encenação serve-se das formas de cultura menos eruditas - circo, musical, atuações em feiras - com o intuito de atingir os russos iletrados, levando a eles o ideal comunista.

Meyerhold dispensa o proscênio pela primeira vez e substitui o palco plano por uma espécie de palco em diferentes níveis, sem cortinas frontais ou cenários móveis. O cenário Meyerholdiano ganhou a presença de máquinas, andaimes, discos giratórios, trapézios proporcionando uma nova ambientação. 
Devido a essas modificações cenográficas, a iluminação tem papel importantíssimo. É a luz da cena que determina a mudança entre os diversos ambientes formados nessa nova arquitetura do espaço cênico.

O figurino desta estética teatral deve ser composto de trajes adequados a toda essa nova ambientação. De certa forma, as vestimentas em cena deixam de ser figurinos realistas para comporem trajes confortáveis à movimentação nesse novo palco.

A música na encenação meyerholdiana auxilia no projeto de criação de um teatro popular. Aparece em musicais, ligada a elementos do folclore.

Quanto ao texto escrito, o teatro de Meyerhold luta pela desverbalização no teatro. Seu objetivo é utilizar a pantomima e o folclore em uma cena estilizada, simples e mais próxima do povo.

Os atores devem vestir e operar toda essa mecanicidade com movimentos mecânicos ou acrobacias. Para Meyerhold, a verdadeira expressão cênica é realizada não por palavras, mas por gestos, olhares, passos, atitudes, ou seja, pela expressão corporal. Na sua concepção, o ator tem que executar o máximo de movimentos em um mínimo de tempo de reação possível, indo contra a expressão dos estados da alma do Teatro Psicológico. O movimento do ator deve ser preciso, cronométrico e para isso seu corpo deveria ser como uma máquina bem oleada. Nessa estética, o ator é o agente fundamental da cena.

O diretor no teatro de Meyerhold tem um papel democrático como encenador, fugindo da chamada "ditadura do encenador" do Teatro Realista/Naturalista. Sua função é de organizar os elementos da encenação, mas o processo criador é dividido com todo o corpo de trabalho e também com o público.

Assim, o teatro concebido por Meyerhold mostra-se como oposto ao de Stanislavski, ou seja, seu termo contrário. Toda a encenação é voltada a técnicas nãoilusionistas, em constante contato com a platéia, que deveria funcionar como um dos criadores ativos do espetáculo. Essa estética enquadra-se no não-distanciamento, pois se opõe à distância preconizada entre encenação e platéia, mas não chega a aproximá-las de forma tão visceral como o Teatro da Crueldade. O teatro meyerholdiano vai em busca de uma simplificação que atinja o povo de forma ativa. As encenações poderiam ocorrer em teatros, cujos espaços cênicos seriam modificados, ou em feiras livres. Os atores eram quase que performáticos e a verbalização, diminuta. Não há o cenário realista. A platéia é convidada a cobrir as lacunas do espetáculo com sua imaginação, mas também com vaias, aplausos, chegando a fazer parte do coro em alguns espetáculos. Há entre espectador e encenação uma relação frontal, que nega o distanciamento. Assim, uma alteração importante na relação entre atores e espectadores ocorre entre o teatro da não-aproximação e o do não-distanciamento. O público, treinado por anos a permanecer em um silêncio estático, é estimulado a criar e a se manifestar. O teatro passa a ser um espaço de discussão política e comunhão entre encenação e platéia.

\section{5. O quadrado semiótico}

Uma vez expostas as principais características de cada encenação, condicionadas por categorias formais distintas, mostra-se possível a elaboração de um 
quadrado semiótico, em que estejam presentes as categorias formais de aproximação e distanciamento com seus termos contrários e contraditórios.

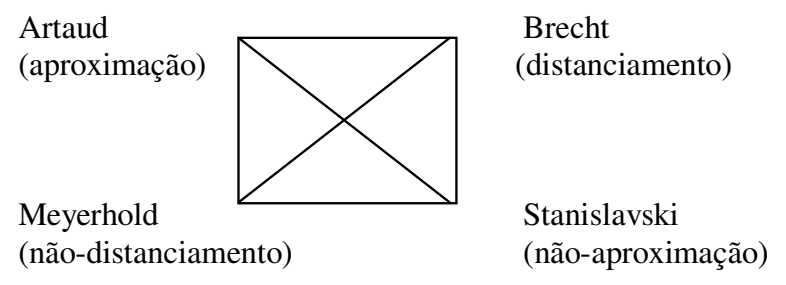

O teatro artaudiano é o teatro da aproximação, pois chega a considerar a platéia como elemento cênico. O teatro de Stanislavski é o da não-aproximação, pois nega a aproximação entre encenação e platéia quando impõe a quarta parede, mas não chega ao distanciamento, pois estabelece a identificação da platéia. O teatro de Brecht é o teatro do distanciamento, pois utiliza recursos para afastar a platéia da encenação evitando qualquer espécie de troca ilusionista. O teatro de Meyerhold é do não-distanciamento, pois nega o distanciamento ao organizar-se em torno da participação criadora da platéia na encenação, mas não chega a apresentar uma estética da aproximação por não compartilhar sensações viscerais e não considerar a platéia como elemento cênico.

\section{REFERÊNCIAS BIBLIOGRÁFICAS}

ARTAUD, A. O teatro e seu duplo. São Paulo: Max Limonad, 1990.

BARROS, D.L.P. de. Teoria do discurso: fundamentos semióticos. São Paulo: Atual, 1988.

BRECHT, B. Estudos sobre teatro. Rio de Janeiro: Nova Fronteira, 1958.

FIORIN, J. L. Elementos de análise do discurso. São Paulo: Contexto/EDUSP, 1989.

ROUBINE, J. A linguagem da encenação teatral. Rio de Janeiro: Jorge Zahar, 1998.

SAUSSURE, F. Curso de lingüística geral. São Paulo: Cultrix, 1969.

STANISLAVSKI, C. A construção da personagem. Rio de Janeiro: Civilização Brasileira, 1976.

THOSS \& BOUSSIGNAC. Brecht para iniciantes. São Paulo: Brasiliense, 1990.

\section{Como citar este artigo:}

FERNANDES, Janaína de Mello. A enunciação na encenação teatral. Estudos Semióticos, Número 2, São Paulo, 2006. Disponível em <www.fflch.usp.br/dl/semiotica/es>. Acesso em "dia/mês/ano". 